\title{
Cutaneous leishmaniasis in Switzerland: first experience with species-specific treatment
}

\author{
V. Mosimann · A. Neumayr $\cdot$ C. Hatz $\cdot$ \\ J. A. Blum
}

Received: 14 March 2013/Accepted: 21 June 2013/Published online: 9 July 2013

(C) Springer-Verlag Berlin Heidelberg 2013

\begin{abstract}
Background Different species of the genus Leishmania can cause cutaneous (CL) and mucosal leishmaniasis (ML). PCR-based tests allow a rapid diagnosis and determination of the species, thereby enabling species-oriented treatment. Such treatment procedures have not been evaluated to date. Methods Patients presenting with CL and ML between 1999 and 2011 were analysed retrospectively. PCR technology was used to diagnose the disease and identify the protozoan to the species level.

Results A total of 61 cases were reviewed, including 58 patients with CL and three patients with ML. Treatment was effective in most patients. Treatment failure was reported in six patients with L. panamensis (one fluconazole, one ketoconazole), L. infantum (one excision, one fluconazole), $L$. tropica (one paromomycin/methylbenzethonium), L. braziliensis (1 paromomycin/methylbenzethonium). In 11 (18\%) patients treatment had to be interrupted due to adverse events, and in eight patients (13 $\%)$ a second treatment had to be applied. Treatment with meglumine antimoniate had to be interrupted in six patients, with QTc prolongation the reason for the interruption in three patients.

Conclusions Species-related, targeted treatment resulted in good responses in CL and ML lesions. Treatment recommendations for $L$. panamensis were changed from ketoconazole to miltefosine because of new evidence of
\end{abstract}

V. Mosimann · A. Neumayr · C. Hatz · J. A. Blum $(\square)$

Swiss Tropical and Public Health Institute, Socinstrasse 57, 4002 Basel, Switzerland

e-mail: johannes.blum@unibas.ch

V. Mosimann - A. Neumayr - C. Hatz · J. A. Blum

University of Basel, Basel, Switzerland treatment failures. Meglumine antimoniate should be restricted to species with poor response to alternative medications and should be used with caution in patients older than 60 years because of its toxicity. Treatment in immunosuppressed patients was successful, but relapses were observed when the immune system could not be restored. This is the first report on L. aethiopica from Egypt.

Keywords Cutaneous leishmaniasis $\cdot$ Mucosal leishmaniasis · Treatment · Miltefosine $\cdot$ Meglumine antimoniate

\section{Introduction}

Leishmaniasis is an infection caused by intracellular protozoan parasites of the genus Leishmania and is transmitted by various species of sand flies. The clinical manifestations are wide and include papulo-nodular and ulcerative skin lesions and destructive mucosal inflammation. With regard to cutaneous leishmaniasis (CL) and mucocutaneous leishmaniasis (ML), the parasite species are divided into old world (OW) (Southern Europe, the Middle East, Asia, Africa) and New World (NW) leishmaniasis (Latin America).

Imported cases of leishmaniasis have become more frequent in Europe over the past years due to increased travel to risk areas. Standardised species identification and treatment protocols are warranted to provide the patients with the best possible treatment.

Leishmania species have different sensitivities to antileishmanial drugs. The wide availability of PCR genotyping tools allows a rapid determination of species, which is a precondition for species-adapted treatment. National consortia and international networks (Germany, France, UK, 
World Health Organization) and several authors have published guidelines for the treatment of CL in the past decade [1-8]. Most of these guidelines concentrate on species-oriented treatment. The guidelines harmonise many issues, but there are some differences. The recommendations are usually based on data from endemic regions, but travellers could have different treatment response to antileishmanial drugs than the endemic population with repeated contact to Leishmania parasites and more treatment options.

In this report, we summarize the clinical experiences of 61 travellers with CL or ML who were treated with species-oriented therapy.

\section{Patients and methods}

This study was a retrospective analysis of patients with CL or ML diagnosed by PCR-based tests from January 1999 to December 2011 at the Swiss Tropical and Public Health Institute (Swiss TPH). The study cohort comprised 61 patients who met these criteria. The following data were extracted from the medical records: age, sex, endemic region(s) visited, dates of visit in endemic regions, number, size and site of the lesion(s), results of PCR-based test regarding species specification and treatment modalities (effectiveness, adverse events).

Patients were mostly treated according to the recommendations published between 1994 and 2009 [1-3] and followed-up by the Swiss TPH, hospitals or their general physicians.

The clinical cure of the lesion was defined as complete re-epithelialization or/and flattening of papules and nodules before day 90 after treatment initiation. Relapses were defined by the appearance of new lesions after clinical cure within 12 months.

DNA extraction and PCR amplification of the polymorphic miniexon marker was performed as described previously $[9,10]$. The amplicon size was indicative of Leishmania species complexes. For species determination, PCR products were digested with four to six restriction enzymes depending on the complex identified, and the restriction fragments were separated by polyacrylamide gel electrophoresis; the patterns of restriction fragments were then compared to those from reference strains [9].

Ethical considerations in line with those of the 'Ethikkommission beider Basel' (EKBB) (3rd October 2011) and the 'Commission cantonale (VD) d'éthique de la recherche sur l'être humain' (20th April 2012). Only patients with signed informed consent were included.

\section{Results}

Patients and description of the lesions

Between January 1999 and December 2011 CL was diagnosed in 58 patients and ML in three patients. Of the 61 patients, 23 (38\%) were female and $38(62 \%)$ were male, and age at the time of diagnosis ranged from 1 to 86 (median 34.5) years (Table 1). The clinical features, such as number of lesions and size of lesion, are summarized in Table 1 . In patients with $\mathrm{CL}$, the lesions were localized on the arms $(n=21 ; 30 \%)$, legs $(n=21 ; 30 \%)$, head $(n=14 ; 20 \%)$ and trunk $(n=14 ; 20 \%)$. One immunosuppressed patient presented with disseminated CL (see below). In the three patients with ML, the lesions were localized on the mouth ( $n=2 ; L$. infantum) and in the nose ( $n=1 ;$ L. braziliensis $)$.

The most likely country of acquisition of the infection and the involved species are described in Table 2.

\section{Treatment}

The species-specific treatment response is described in Table 3. In $11 / 61(18 \%)$ patients treatment had to be interrupted due to adverse event(s); in eight (13\%) patients a second treatment had to be applied.

Systemic meglumine antimoniate treatment had to be interrupted in 6/18 (33\%) patients due to adverse event(s) and could not be resumed in the following five patients:

- 73-year-old patient: QTc prolongation and elevated liver enzymes [11];

- 64-year-old patient: skin eruption, hypokalaemia $(2.3 \mathrm{mmol} / \mathrm{l})$ and QTc prolongation $(600 \mathrm{~ms})$;
Table 1 Description of the total patient cohort $(n=61)$ and aspects of skin lesions $(n=57)$

$C L$ Cutaneous leishmaniasis, $M L$ mucocutaneous leishmaniasis

${ }^{\text {a }}$ Number of patients for whom data were not available

\begin{tabular}{llll}
\hline Patients/description of lesions & Old World cases $(n=36)$ & New World cases $(n=25)$ & All cases \\
\hline Gender, $(n)$ male/female & $19 / 17$ & $19 / 6$ & $38 / 23$ \\
Age (years), median (range) & $43(1-86)$ & $31(9-71)$ & $34.5(1-86)$ \\
CL/ML $(n)$ & $34 / 2$ & $24 / 1$ & $58 / 3$ \\
Number of lesions, mean (range) & $2.9(1-13)\left(10^{\mathrm{a}}\right)$ & $2(1-6)\left(4^{\mathrm{a}}\right)$ & $2.5(1-13)$ \\
& & & $\left(14^{\mathrm{a}}\right)$ \\
Solitary/multiple, $(n)$ & $10 / 17\left(9^{\mathrm{a}}\right)$ & $12 / 9\left(4^{\mathrm{a}}\right)$ & $22 / 26\left(13^{\mathrm{a}}\right)$ \\
Size of lesion $(\mathrm{cm})$, mean (range) & $2.6(1-6)\left(13^{\mathrm{a}}\right)$ & $3.2(1-6)\left(9^{\mathrm{a}}\right)$ & $2.9(1-6)$ \\
& & & $\left(22^{\mathrm{a}}\right)$ \\
\hline
\end{tabular}


Table 2 Country of acquisition of leishmaniasis and Leishmania species involved $^{\mathrm{a}}$

\begin{tabular}{|c|c|}
\hline Country of acquisition & Number/species \\
\hline \multicolumn{2}{|l|}{ Old World $(n=27)$} \\
\hline \multicolumn{2}{|l|}{ Europe } \\
\hline Macedonia & 1 L. infantum \\
\hline France & 1 L. infantum \\
\hline Sicily & 1 L. infantum \\
\hline \multicolumn{2}{|l|}{ Middle East } \\
\hline Israel & $\begin{array}{l}1 \text { L. infantum, } \\
1 \text { L. major }\end{array}$ \\
\hline Syria & 1 L. tropica \\
\hline \multicolumn{2}{|l|}{ North Africa } \\
\hline Morocco & $\begin{array}{l}3 \text { L. infantum, } \\
4 \text { L. major }\end{array}$ \\
\hline Egypt & 1 L. aethiopica \\
\hline Tunisia & 1 L. major \\
\hline Algeria & 1 L. donovani \\
\hline Sudan & 1 L. major \\
\hline Canaries & 1 L. infantum \\
\hline \multicolumn{2}{|l|}{ Sub-Saharan Africa } \\
\hline Burkina Faso & 5 L. major \\
\hline Chad & 1 L. major \\
\hline Kenya & 1 L. major \\
\hline Senegal & 1 L. major \\
\hline \multicolumn{2}{|l|}{ South Asia } \\
\hline Afghanistan & 1 L. tropica \\
\hline \multicolumn{2}{|l|}{ New world $(n=22)$} \\
\hline \multicolumn{2}{|l|}{ Central America } \\
\hline Costa Rica & 4 L. panamensis \\
\hline Guatemala & 1 L. mexicana \\
\hline Panama & 1 L. panamensis \\
\hline \multicolumn{2}{|l|}{ South America } \\
\hline Ecuador & $\begin{array}{l}3 \text { L. braziliensis, } \\
1 \text { L. peruviana }\end{array}$ \\
\hline Bolivia & $\begin{array}{l}3 \text { L. braziliensis, } \\
1 \text { L. peruviana }\end{array}$ \\
\hline Guyana & 5 L. guyanensis \\
\hline \multirow[t]{2}{*}{ Brazil } & 1 L. naiffi \\
\hline & 1 L. chagasi \\
\hline Peru & 1 L. peruviana \\
\hline
\end{tabular}

${ }^{a}$ Data were available for 49 patients; for 12 patients no data were available

- 44-year-old patient: skin reaction, myalgia, QTc prolongation $(513 \mathrm{~ms})$;

- 49-year-old patient: skin reaction;

- 32-year-old patient: local reaction.

In the sixth patient (aged 44 years) who had elevated liver enzymes, treatment was resumed after 3 days.
Table 3 Response of treatment according to species

\begin{tabular}{llll}
\hline Leishmania species & Treatment & Successful & $\begin{array}{l}\text { No } \\
\text { response }\end{array}$
\end{tabular}

\begin{tabular}{|c|c|c|c|c|}
\hline \multicolumn{5}{|l|}{ Old World $(n=36)$} \\
\hline \multirow[t]{4}{*}{ L. major $(n=17)$} & $\begin{array}{l}\text { Fluconazole/ } \\
\text { ketoconazole }\end{array}$ & 10 & 0 & 0 \\
\hline & Leishcutan ${ }^{\circledR a}$ & 3 & 0 & 0 \\
\hline & Antimonials & 1 & 0 & 0 \\
\hline & $\begin{array}{l}\text { Cryo-/ } \\
\text { thermotherapy }\end{array}$ & 3 & 0 & 0 \\
\hline \multirow{6}{*}{$\begin{array}{l}\text { L. infantum/ } \\
\text { donovani }(n=14)\end{array}$} & Miltefosine & $4\left(1 x^{b}\right)$ & 0 & 0 \\
\hline & Antimonials & $3\left(1 x^{b}\right)$ & 0 & 0 \\
\hline & Leishcutan ${ }^{\circledR a}$ & 2 & 0 & 0 \\
\hline & Amphotericin B & $3\left(2 x^{b}\right)$ & 0 & 0 \\
\hline & Fluconazole & 0 & 1 & 0 \\
\hline & $\begin{array}{l}\text { Cryo-/ } \\
\text { thermotherapy }\end{array}$ & 5 & 0 & 1 \\
\hline \multirow[t]{4}{*}{ L. tropica $(n=4)$} & Fluconazole & 2 & 0 & 0 \\
\hline & $\begin{array}{l}\text { Itraconazole/ } \\
\text { cryotherapy }\end{array}$ & 1 & 0 & 0 \\
\hline & $\begin{array}{l}\text { Infiltration with } \\
\text { antimonials }\end{array}$ & 1 & 0 & 0 \\
\hline & Leishcutan $^{\circledR a}$ & 0 & 1 & 0 \\
\hline $\begin{array}{l}\text { L. aethiopica } \\
(n=1)\end{array}$ & Miltefosine & 1 & 0 & 0 \\
\hline
\end{tabular}

New World $(n=25)$

\begin{tabular}{|c|c|c|c|}
\hline L. braziliensis & Antimonials & 6 & 0 \\
\hline$(n=8)$ & Amphotericin B & 1 & 0 \\
\hline & Pentamidine & 1 & 0 \\
\hline & Leishcutan ${ }^{\circledR a}$ & 0 & 1 \\
\hline L. guyanensis & Pentamidine & 4 & 0 \\
\hline & Antimonials & 1 & 0 \\
\hline & $\begin{array}{l}\text { Infiltration with } \\
\text { antimonials }\end{array}$ & 1 & 0 \\
\hline L. panamensis & Miltefosine & 2 & 0 \\
\hline$(n=5)$ & Ketoconazole & 2 & 1 \\
\hline & Fluconazole & 0 & 1 \\
\hline & Antimonials & 1 & 0 \\
\hline $\begin{array}{l}\text { L. peruviana } \\
(n=3)\end{array}$ & Antimonials & 3 & 0 \\
\hline $\begin{array}{l}\text { L. mexicana } \\
(n=1)\end{array}$ & $\begin{array}{l}\text { Spontaneous } \\
\text { disappearance }\end{array}$ & 1 & 0 \\
\hline L. naiffi $(n=1)$ & Leishcutan ${ }^{\circledR a}$ & 1 & 0 \\
\hline L. chagasi $(n=1)$ & Amphotericin B & 1 & 0 \\
\hline
\end{tabular}

${ }^{\text {a }}$ Leishcutan ${ }^{\circledR}: 15 \%$ paromomycin and $12 \%$ methylbenzethonium ointment

${ }^{\mathrm{b}}$ Same patient with Good syndrome, mucosal leishmaniasis and 3 relapses treated with miltefosine $1 \times$, antimonials $1 \times$, amphotericin $\mathrm{B} 2 \times$; (for details see text)

Pentamidine treatment had to be interrupted in $2 / 6$ patients and could not be resumed in both cases:

- 32-year-old patient: anaphylactic shock;

- 61-year-old patient: aseptic abscess at injection site. 
Miltefosine treatment had to be interrupted in $1 / 7$ patients and could be resumed [11]:

- 64-year-old patient with vomiting and disturbances of kidney function (creatinine $160 \mu \mathrm{mol} / \mathrm{l}$ ) and hypokalaemia $(2.5 \mathrm{mmol} / \mathrm{l})$. After oral rehydration treatment could successfully be completed.

Local treatment consisted of paromomycin $15 \% / m e t h-$ zylbenzethonium $12 \%$ (Leishcutan $^{\circledR}$ ) and intralesional meglumine antimoniate, respectively. Treatment was interrupted in $1 / 8$ patients (Leishcutan ${ }^{\circledR}$ ) and $1 / 4$ patients (meglumine antimoniate) due to strong local reactions.

\section{Pregnancy}

Three CL patients were in their last trimester of pregnancy at the time of diagnosis: one patient was treated with excision of the lesion twice, one patient showed spontaneous cure of the lesions after delivery and one patient was treated with fluconazole $200 \mathrm{mg} /$ day for 6 weeks. All children were born healthy.

\section{Immunusuppression}

Three patients were treated in the context of relevant immunosuppression:

- A mucosal leishmaniasis due to L. infantum in a patient with Good syndrome responded well to treatment with meglumine antimoniate. Three relapses after $2-3$ years responded well to amphotericin $\mathrm{B}(2 \times)$ and miltefosine $(1 \times)$.

- A patient with rheumatoid arthritis developed disseminated CL after the dose of a tumour necrosis factoralpha (TNF- $\alpha$ ) inhibitor had been increased. Treatment with the TNF- $\alpha$ inhibitor was discontinued and the lesions healed under treatment with meglumine antimoniate. Treatment with the TNF- $\alpha$ inhibitor could be restarted at a lower dosage without relapse of CL.

- A patient with ankylosing spondylitis (Bechterew's disease) developed multiple lesions at both auricles (ears) under treatment with etanercept $50 \mathrm{mg} /$ week. Treatment with the TNF- $\alpha$ inhibitor was stopped. The lesions healed under treatment with miltefosine. Treatment with the TNF- $\alpha$ inhibitor could be restarted at a lower dosage without relapse of CL.

\section{Discussion}

Species-oriented treatment has been established in travellers $[1-3,5,6]$ for more than one decade following the increased availability of PCR-based diagnostic techniques.
However, the large number of different species in a relatively low number of patients with $\mathrm{CL}$ or ML does not allow a comprehensive evaluation of the proposed recommendations. Only a multicentre survey study will provide sufficient power to draw conclusions on treatment outcome of different species. Such a study has recently been started and will last for several years in order to collect data on adequate numbers of patients. Here, we present our limited experiences with species-oriented treatment.

The cases presented here cover a wide variety of $\mathrm{CL}$ species originating from 24 countries, mainly from Latin America and the Mediterranean region, and less frequently from Sub-Saharan Africa and South Asia. Since more than one species is endemic in most countries, PCR-based techniques are needed for species determination. The species reported in our study are endemic in the visited countries with one exception: L. aethiopica was detected in a patient who has never travelled to a country endemic for L. aethiopica [12]. The most likely country of acquisition is Egypt, but this individual had also travelled to Namibia, South Africa, Zimbabwe, and Southern France.

Systemic treatment was administered to patients with New World leishmaniasis (except L. mexicana), ML, established metastatic spread to lymphnodes, localisation in the face (nose, eyelids) or close to joints, multiple or large lesions or those with no response to topical treatment. However a recent analysis of the available literature revealed that local treatment might be considered as a valuable treatment option for travellers suffering from NW CL provided that there are no risk factors for developing ML, such as multiple lesions, large lesions $\left(>4 \mathrm{~cm}^{2}\right)$, localisation of the lesion on the head or neck, immunosuppression or acquisition of infection in Bolivia [13].

The cure rates of L. major were excellent with local and systemic treatment. The only treatment failure was observed in a case where toxicity of meglumine antimoniate demanded treatment cessation. However, these good results have to be compared to high spontaneous cure rates of $53 \%$ at 8 weeks [14], from 40 to $70 \%$ at 3 months and close to $100 \%$ at 12 months [15]. For small lesions, simple wound care and observation should be an option, and the use of the toxic systemic meglumine antimoniate should be restricted to lesions for which other treatments have failed.

Little data have been published on the treatment of $L$. infantum lesions. We found that local treatment was effective in most cases and that miltefosine or liposomal amphotericin B were effacious treatment options in cases where systemic treatment was indicated.

Local treatment and fluconazole was effective in four patients with CL due to L tropica. According to recent data cryotherapy combined with intralesional antimonials produces excellent cure rates in CL due to $L$. major and $L$. tropica, and this treatment combination should be the first- 
line treatment for local therapy [16-18]. The spontaneous cure rates of CL due to L. tropica are considerable lower than those observed in CL due to L. major, reaching $1 \%$ at 3 months, $68 \%$ at 12 months [15] and usually close to $100 \%$ in 6 months to 3 years.

Systemic meglumine antimoniate has been the first-line treatment for leishmaniasis caused by L. braziliensis for decades and was successfully used in the patients included in our study. Local treatment should only be applied when the above-mentioned exclusion criteria are taken into account [13].

Pentamidine is widely used to treat CL due to $L . g u$ yanensis, and all patients included in our study who received pentamidine were cured. If pentamidine is contraindicated, miltefosine is a possible alternative [19].

In previous recommendations ketoconazole was the treatment of first choice for $L$. panamensis lesions due to its low toxicity and cost. However, treatment guidelines were changed due to a number of developments. Firstly, there have been new publications on miltefosine showing that the cure rates with miltefosine are superior to placebo (91 vs. $38 \%$, respectively) [20] and similar to (60 vs. $72 \%$ ) [21] or higher than (92 vs. $63 \%$ ) [22] those obtained using pentavalent antimonials. Secondly, a critical analysis of the existing literature revealed that the previous recommendations on the use of ketoconazole were based on only one study with a limited number of patients $(n=9)$ and a cure rate of $76 \%$ [23]. Thirdly, experiences in the reported collective: ketoconazole only cured $2 / 4$ patients, but miltefosine achieved a cure in two patients during the study period and in an additional four patients during the poststudy period.

Due to adverse events, treatment had to be interrupted in $18 \%$ of the cases, and an alternative treatment had to be applied in $13 \%$ of patients. Meglumine antimoniate was responsible for the most dangerous adverse events, including QTc prolongation and severe hypokaliaemia (3 patients). These adverse events highlight the need to perform electrocardiography (ECG) and electrolyte controls once to twice per week. Of note is that the average age of these three patients was 60 years, which is much higher than the average age of 33 years in patients without relevant QTc prolongation. Because of its toxicity, meglumine antimoniate should only be used in cases where it is superior to alternative therapy (e.g. against $L$. braziliensis) or after alternative treatments have failed. In elderly patients ( $>60-65$ years) meglumine antimoniate should be used with caution: ECG, kidney function, electrolytes, liver tests and haematological parameters need to be followed up twice weekly) [24].

It is notable that treatment with pentamidine had to be interrupted in two patients because of an anaphylactic reaction in one patient and an aseptic abscess at the injection sites in another patient. Therefore, we propose that pentamidine be administered as an intravenous infusion and not as an intramuscular injection. The paromomycin/methylbenzethonium ointment led to interruption of treatment due to a strong local inflammation, but treatment could be resumed and the lesion was cured.

Our case of the patient with Good syndrome demonstrated that relapses have to be expected if restoration of the immune system is not achieved. The increasing number of patients treated with immune-modulating drugs is associated with the risk of developing CL and ML. As the exposure often dated back many months or even years and the initially treating physicians were often not familiar with the clinical presentation, diagnosis of CL was delayed in some of the patients described here.

In both patients with rheumatoid diseases, treatment with the TNF- $\alpha$ inhibitor was stopped during antileishmanial treatment but was resumed (at a lower dosage) after successful cure of the skin lesions. No relapse was observed after treatment with anti-TNF- $\alpha$ inhibitor therapy was resumed.

The limitations of this study include the small number of patients and the fact that not all patients were treated according to our recommendations. Some recommendations have been changed due to new evidence. A further reason for the different treatment approach to some species (mainly L. infantum) is the lack of published evidence and the variable availability of some treatments.

\section{Conclusions}

Species-specific treatment showed good results in CL and ML lesions. L. panamensis treatment recommendations were changed from ketoconazole to miltefosine because of recent publications on miltefosine, a critical review of ketoconazole and the observed treatment failures. Meglumine antimoniate should be restricted to species which respond poorly to alternative medications. The drug should be used with caution in patients older than 60 years because of its toxicity. Treatment in immunosuppressed patients was successful, but relapses were observed when the immune system could not be restored. This is the first report on L. aethiopica from Egypt.

Conflict of interest We declare that there is no conflict of interests.

\section{References}

1. Blum J, Desjeux P, Schwartz E, Beck B, Hatz C. Treatment of cutaneous leishmaniasis among travellers. J Antimicrob Chemother. 2004;53:158-66. 
2. Blum JA, Hatz CF. Treatment of cutaneous leishmaniasis in travelers 2009. J Travel Med. 2009;16:123-31.

3. Blum J, Hatz C, Junghanss T. The therapy of cutaneous and mucocutaneous leishmaniasis. Dtsch Med Wochenschr. 1994; 119:1169-72.

4. Schwartz E, Hatz C, Blum J. New world cutaneous leishmaniasis in travellers. Lancet Infect Dis. 2006;6:342-9.

5. Boecken G, Sunderkotter C, Bogdan C, et al. Diagnosis and therapy of cutaneous and mucocutaneous leishmaniasis in Germany. J Dtsch Dermatol Ges. 2011;9:1-51.

6. Mitropoulos P, Konidas P, Durkin-Konidas M. New World cutaneous leishmaniasis: updated review of current and future diagnosis and treatment. J Am Acad Dermatol. 2010;63:309-22.

7. Goto H, Lindoso JA. Current diagnosis and treatment of cutaneous and mucocutaneous leishmaniasis. Expert Rev Anti Infect Ther. 2010;8:419-33.

8. Buffet PA, Rosenthal E, Gangneux JP, et al. Therapy of leishmaniasis in France: consensus on proposed guidelines. Presse Med. 2011;40:173-84.

9. Marfurt J, Niederwieser I, Makia D, Beck H-P, Felger I. Diagnostic genotyping of Old and New World Leishmania species by PCR-RFLP. Diagn Microbiol Infect Dis. 2003;46:115-24.

10. Marfurt J, Nasereddin A, Niederwieser I, Jaffe CL, Beck HP, Felger I. Identification and differentiation of Leishmania species in clinical samples by PCR amplification of the miniexon sequence and subsequent restriction fragment length polymorphism analysis. J Clin Microbiol. 2003;41:3147-53.

11. Neumayr ALC, Walter C, Stoeckle M, Braendle N, Glatz K, Blum JA. Successful treatment of imported mucosal Leishmania infantum leishmaniasis with miltefosine after severe hypokalemia under meglumine antimoniate treatment. J Travel Med. 2012;19: 124-6.

12. Pratlong F, Dereure J, Ravel C, et al. Geographical distribution and epidemiological features of Old World cutaneous leishmaniasis foci, based on the isoenzyme analysis of 1048 strains. Trop Med Int Health. 2009;14:1071-85.

13. Blum J, Lockwood DNJ, Visser L, et al. Local or systemic treatment for new world cutaneous leishmaniasis? Re-evaluating the evidence for the risk of mucosal leishmaniasis. Int Health. 2012;4:153-63.
14. Nassiri-Kashani M, Firooz A, Khamesipour A, et al. A randomized, double-blind, placebo-controlled clinical trial of itraconazole in the treatment of cutaneous leishmaniasis. J Eur Acad Dermatol Venereol. 2005;19:80-3.

15. Bailey MS, Lockwood DN. Cutaneous leishmaniasis. Clin Dermatol. 2007;25:203-11.

16. Asilian A, Sadeghinia A, Faghihi G, Momeni A. Comparative study of the efficacy of combined cryotherapy and intralesional meglumine antimoniate (Glucantime) vs. cryotherapy and intralesional meglumine antimoniate (Glucantime) alone for the treatment of cutaneous leishmaniasis. Int J Dermatol. 2004;43: 281-3.

17. Eldarouti MA, Alrubaie SM. Cutaneous leishmaniasis-treatment with combined cryotherapy and intralesional stibogluconate injection. Int J Dermatol. 1990;29:56-9.

18. Salmanpour R, Razmavar MR, Abtahi N. Comparison of intralesional meglumine antimoniate, cryotherapy and their combination in the treatment of cutaneous leishmaniasis. Int J Dermatol. 2006;45:1115-6.

19. Chrusciak-Talhari A, Dietze R, Chrusciak TC, et al. Randomized controlled clinical trial to access efficacy and safety of miltefosine in the treatment of cutaneous leishmaniasis caused by Leishmania (Viannia) guyanensis in Manaus. Brazil. Am J Trop Med Hyg. 2011;84:255-60.

20. Soto J, Arana A, Toledo J, et al. Miltefosine for new world cutaneous leishmaniasis. Clin Infect Dis. 2004;38:1266-72.

21. Velez I, Lopez L, Sanchez X, Mestra L, Rojas C, Rodriguez E. Efficacy of miltefosine for the treatment of American cutaneous leishmaniasis. Am J Trop Med Hyg. 2010;83:351-6.

22. Rubiano LC, Miranda MC, Arenas SM, et al. Noninferiority of miltefosine versus meglumine antimoniate for cutaneous leishmaniasis in children. J Infect Dis. 2012;205:684-92.

23. Saenz RE, Paz H, Berman JD. Efficacy of ketoconazole against Leishmania braziliensis panamensis cutaneous leishmaniasis. Am J Med. 1990;89:147-55.

24. Wise ES, Armstrong MS, Watson J, Lockwood DN. Monitoring toxicity associated with parenteral sodium stibogluconate in the day-case management of returned travellers with new world cutaneous leishmaniasi. PLoS Negl Trop Dis. 2012;6:e1688. 